\title{
TURISMO E AFIRMAÇÃO DA IDENTIDADE CULTURAL: IMPACTOS PSICOSSOCIAIS DA ATIVIDADE TURÍSTICA EM DIAMANTINA
}

TOURISM AND AFFIRMATION OF CULTURAL IDENTITY: PSYCHOSOCIAL IMPACTS OF TOURISM IN DIAMANTINA

\section{TURISMO Y AFIRMACIÓN DE LA IDENTIDAD CULTURAL: LOS IMPACTOS PSICOSOCIALES DEL TURISMO EN DIAMANTINA}

Diego Rodrigues da Silva

Bacharel em Humanidades - UFVJM Mestrando em Turismo e Desenvolvimento - UFPR

\section{Paulo Afranio Sant'Anna}

Universidade Federal dos Vales de Jequitinhonha e Mucuri -

FIH-Professor Adjunto III Coordenador da Licenciatura em Educação do Campo e do PIBID Diversidade.

Professor do Programa de Mestrado Ensino em Saúde-UFVJM Professor Colaborador do Programa de Mestrado Pro-Mestre - UFMG

Data de Submissão: 30/08/2014 Data de Aprovação: 01/03/2015 
Resumo: A presente pesquisa tem por objetivo investigar os impactos psicossociais na comunidade de Diamantina decorrentes do contato intercultural impulsionado pela atividade turística, enfocando, mais especificamente, nas questões identitárias do diamantinense, as quais se manifestam e se afirmam no contato com o turista. Por meio da produção de um grupo focal com representantes dos principais setores da atividade turística diamantinense, pretendeu-se identificar quais os impactos da atividade turística para a identidade cultural dos moradores de Diamantina. Por meio da análise de conteúdo, foi possível identificar indicadores que foram agrupados em três categorias: cultura da hospitalidade, cultura garimpeira e cultura refinada. Os resultados sugerem que esses três aspectos da identidade diamantinense são impactados não só pelo turismo, mas em conjunto com outros fenômenos de ordem econômica e social, como a criação da universidade federal e o fim do garimpo. Nesse contexto, o turismo ainda não se inscreve como traço identitário.

Palavras-chave: Identidade. Turismo. Impacto do turismo.

Abstract: This research investigates the psychosocial impacts on the community of Diamantina, resulting from intercultural contact driven by tourism, focusing more specifically on issues of the identity of the local residents of the town, who give their views and assert themselves in their contact with tourists. Through the production of a focus group with representatives of the main sectors of tourism in the town, we seek to identify the impacts of tourism on the cultural identity of the inhabitants of Diamantina. Through content analysis, indicators were identified, which were then grouped into three categories; culture of hospitality, diamond mining culture, and refined culture. The results suggest that these three aspects of identity of the local residents are impacted not only by tourism, but in conjunction with other economic and social phenomena, 
such as the creation of the federal university and the end of diamond mining. In this context, tourism has not yet become part of the local identity.

Keywords: Identity. Tourism. Tourism impact.

Resumen: Este estudio tiene como objetivo investigar los impactos psicosociales en la comunidad de Diamantina como resultado del contacto intercultural impulsado por la actividad turística, centrándose más concretamente en los temas de la identidad diamantinense, que se manifiestan y se afirman en contacto con el turista. A través de la producción de un grupo de discusión con representantes de los principales sectores de la actividad turística en Diamantina, se intentó identificar los impactos del turismo sobre la identidad cultural de los habitantes de Diamantina. A través del análisis de contenido fue posible identificar los indicadores, que fueron agrupados en tres categorías: la cultura de la hospitalidad, la cultura minera y la cultura refinada. Los resultados sugieren que estos tres aspectos de la identidad diamantinense se ven afectados no solo por el turismo, sino también en combinación con otros fenómenos de orden económico y social, como la creación de la universidad federal y el fin de la minería. En este contexto, el turismo aún no se ha inscrito como rasgo de identidad.

Palabras clave: La identidad. El turismo. El impacto del turismo.

\section{INTRODUÇÃO}

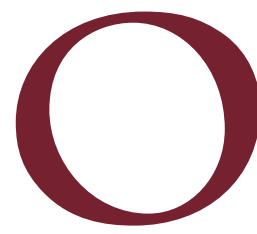

turismo é comumente associado à globalização e, como tal, se torna um "complexo processo de interações transfronteiriças e transnacionais de sistemas de produção, de transferências de capitais, de uso e disseminação da informação e da tecnologia, e até dos deslocamentos de pessoas em escala mundial" (SANTOS, 2002 apud SOARES, 2007, p. 64). Essa migração humana acarreta o contato de culturas 
ISSN: 1983-7151

nacionais e internacionais, na maioria das vezes marcada por alguma reação de conflito, principalmente se as características forem muito discrepantes. Bauman (1999) argumenta que as distâncias já não importam mais, pois o que está sendo apresentado é o fim da geografia em termos de espaço, sendo as fronteiras meras formas simbólicas e sociais. "A distância é um produto social; sua extensão varia dependendo da velocidade com a qual pode ser vencida" (BAUMAN, 1999 p. 19).

Partindo do pressuposto de que a cultura é dinâmica, mutável ao longo do tempo e das gerações, podendo ser transformada por novos elementos que se agregam ou se associam a ela, faz-se necessário pensar e investigar a respeito das possíveis consequências e implicações do contato entre as diversas culturas que se encontram dentro de um território turístico em potencial. Essa convivência torna-se ainda mais eminente na contemporaneidade com a expansão da globalização, fenômeno que implicitamente promove uma maior visibilidade de diversos ambientes culturais principalmente por meio dos meios de comunicação de massa, o que motiva as pessoas a viajarem para os quatro cantos do mundo. Sociedades antes isoladas, intocadas e invisíveis à população não local, que apresentam um alto nível de preservação da sua cultura, tornam-se atrativos turísticos e passam a ser cada vez mais visitadas por outros povos.

Diante dos pressupostos apresentados, percebe-se que se torna imprescindível investigar e analisar de forma mais detalhada como essas comunidades - aqui representada pela cidade de Diamantina, situada em Minas Gerais - , marcadas por fortes tradições, por uma realidade destoante dos grandes centros urbanos e despreparadas para se adequar às mudanças, encaram as transformações provocadas pela atividade turística. Desta forma, o presente trabalho tem como objetivo geral discutir os impactos psicossociais da atividade turística em Diamantina, a partir da concepção de identidade cultural, mais especificamente, a partir das questões identitárias que se apresentam e se afirmam no contato da população local com o turista. O desenvolvimento do texto está estruturado em três seções: discussão sobre identidade cultural, dimensão conceitual do turismo e seus impactos e contexto histórico de Diamantina atrelado à atividade turística. 
A identidade é um dos principais elementos de formação da personalidade do indivíduo. Definida como um conjunto de características próprias e exclusivas de uma pessoa que lhe dará, portanto, um sentimento de pertença, de inclusão e de fixação em relação a um determinado grupo, a identidade possibilita que o indivíduo tome consciência de si mesmo, perceba o seu papel na sociedade e se sinta parte de um grupo maior que, juntamente com ele, compartilha das mesmas referências (HALL, 1999).

Uma das características essenciais da identidade é que ela só é possível numa relação de alteridade. À medida que há o reconhecimento de um "outro", é possível fazer a distinção entre o eu e esse "outro". Ao identificar-se o "outro", criam-se parâmetros de comparação e referência que permitem perceber as similaridades e as diferenças entre os indivíduos. Nesse sentido, a identidade só se faz a partir do reconhecimento da diferença. Se a identidade marca tudo aquilo que o ser é e apresenta ao mundo, a diferença então tem um caráter de distinção, reafirmando o que outro é, mesmo que de forma sutil e encoberta. Hall (2000), ao trabalhar com as identidades nacionais como elemento chave para a compreensão da mesma, sinalizou, por exemplo, que a afirmação "sou brasileiro" ao mesmo tempo em que afirma a identidade brasileira, nega a estrangeira, delimitando a diferença. Além de serem interdependentes, identidade e diferença são construções sociais e culturais, ao passo que cada cultura vai construindo os seus próprios sistemas simbólicos e representações que formarão a identidade. Nesse contexto, Hall utiliza das identidades nacionais como resultado ou construção de um sentimento de pertencimento em torno da nação (HALL, 2000).

A identidade só aparece como questão em momentos de crise, de confronto, de incertezas, à medida que algo, aparentemente sólido e coerente, é ameaçado pela instabilidade e pela dúvida (HALL, 1999). A tese principal de Hall gira em torno da chamada "crise de identidade" pela qual vem passando o sujeito pós-moderno. "As velhas identidades, que por tanto tempo estabilizaram o mundo social, estão em declínio, fazendo surgir novas identidades e fragmentando o indivíduo moderno, 
até aqui visto como um sujeito unificado" (HALL, 1999, p.7). Essa situação é parte ou resultado de um processo muito maior de mudança, de transformações que vêm provocando um deslocamento das estruturas e dos processos centrais das sociedades modernas e, consequentemente, uma descentração da identidade do sujeito, já que esse processo abala os quadros de referência que ancoravam o homem no mundo social. "Identidades modernas estão sendo descentradas, isto é, deslocadas ou fragmentadas" (HALL, 1999, p. 8). Afirma ainda que a identidade cultural se refere aos aspectos relacionados à pertença a culturas étnicas, raciais, linguísticas, religiosas, regionais e/ou nacionais.

Ao pensar identidade cultural como uma construção espaço-temporal que se configura em torno de uma cadeia de refências e matrizes sociais, é importante destacar o papel da memória, uma vez que memória e identidade se reforçam mutuamente. Wehling (2003) enfatiza as funções da memória em relação à identidade, já que esta é principal finalidade daquela. "A memória do grupo baseia-se essencialmente na afirmação de sua identidade." (p.13). Essa interface também é destacada por Santos (2004) ao apresentar que "a definição da própria identidade cultural implica em distinguir os princípios, os valores e os traços que a marcam, não apenas em relação a si própria, mas frente a outras culturas, povos ou comunidades." (SANTOS, 2004, p.59).

À medida que a memória evoca sentimentos, sensações e lembranças de algo que se desenrolou no passado, considera-se que existem "lugares da memória" (POLLAK, 1992). Ambientes que, pela forte e grandiosa concentração de tradições, elementos históricos de caráter pessoal ou coletivo, conservados de tal forma que parecem retratar de maneira fiel um acontecimento secular referente à capacidade de reprodução atemporal da memória. Ela se faz no presente, criando uma identidade com um tempo histórico que nunca morre. Nesse sentido, a "memória pode ser entendida como a capacidade de relacionar um evento atual com um evento passado do mesmo tipo, portanto como uma capacidade de evocar o passado através do presente." (JAPIASSÚ; MARCONDES, 1996, p.178). A relação existente entre memória e identidade cultural se dá no momento em que esse arcabouço de experiência identifica um grupo e cria um fator de diferenciação entre os demais. À medida que a memória cria um elo de aproximação irreversível aos membros de um mesmo grupo definindo-o 
como tal, ela também se apresenta como um dos elementos fundadores da cultura, pois é um componente particularmente humano de evolução coletiva. Mantém o sentimento de coerência dos indivíduos de um grupo no processo de reconstrução de si (BATISTA, 2005).

A lógica da mudança constante da identidade do sujeito pós-moderno descrita por Hall (1999) difere do sujeito que viveu nas sociedades tradicionais. "Nestas sociedades o passado e os símbolos são valorizados porque contêm e perpetuam a experiência das gerações, onde a tradição é meio de lidar com o tempo e o espaço, inserindo uma continuidade do passado, presente e futuro." (SILVA et al., 2006, p. 9). A tradição tem uma relação construída com o tempo, em que o passado é revivido e renovado a partir de sua continuidade. Significados objetivados que são concebidos por conhecedores permanecem vivos por meio da constante reprodução. Assim, a tradição se mantém por meio da transmissão de conhecimentos de uma importante prática social do grupo, sendo que em alguns casos elas podem ser até mesmo recentes. Além disso, as tradições têm uma origem, mesmo que nem sempre seja possível identificá-la de imediato.

Hobsbaum e Ranger (1997) trabalham com a ideia de que as tradições são inventadas, fruto de uma necessidade inserida num contexto histórico social específico e propício. Ao definir esse conceito, ele salienta que a tradição é "um conjunto de práticas que são reguladas por regras e que tem natureza ritual ou simbólica, visando inculcar certos valores e normas de comportamento através da repetição, implicando numa continuidade em relação ao passado" (HOBSBAUM; RANGER, 1997, p.9). A partir daí, percebe-se o papel da tradição na formação da identidade, pois grande parte dos valores e das práticas adquiridos pelas pessoas são representativos de dinâmicas históricas anteriores que, relacionadas ao presente, servem de referência para a percepção de igualdade social e simbólica de um indivíduo em relação ao seu grupo.

Bauman também analisa a questão da identidade do sujeito pós-moderno, defendendo a tese de um "mundo líquido", numa modernidade que transforma as nossas certezas em incertezas e dúvidas constantes. Nesse contexto, a identidade se constrói por meio das escolhas que o indivíduo é capaz de fazer, reconsiderando as decisões anteriores e se ajustando às novas expectativas, 
tentando "conciliar demandas contraditórias e frequentemente incompatíveis" (BAUMAN, 2005, p.17). Deixa claro que o pertencimento e a identidade não são conceitos fixos, imutáveis e fechados, mas sim "renegociáveis e revogáveis" (BAUMAN, 2005, p.17) Assim, para ele, a identidade não é um conceito fechado e predeterminado, mas um objetivo, uma descoberta, algo que se deve procurar continuamente no desenvolvimento de uma sociedade.

\section{ATIVIDADE TURÍSTICA E SEUS IMPACTOS}

A origem da atividade turística acompanhou o desenvolvimento das sociedades. Desde os primórdios das civilizações é possível verificar a ocorrência de pessoas que viajam segundo distintas motivações, ainda que esses deslocamentos se constituíssem em viagens não frequentes e feitas por grupos específicos. Diante da multiplicidade de conceitos em torno da definição de turismo presentes no meio acadêmico, comprova-se a complexidade do fenômeno, que tem como base e mola propulsora o elemento humano, dicotômico e plural em todas as suas dimensões. Fontoura e Becker (1999) destacam que o turismo é uma atividade humana, ou psico-sociocultural, econômica, política na busca de satisfação pessoal, profissional ou social.

Segundo Beni (2001), existem três abordagens para o estudo do turismo: a econômica, a técnica e a holística. A econômica se embasa nas concepções de ganhos econômicos e empresariais que podem ser gerados pelo turismo. A dimensão técnica deste conceito versa sobre as definições de turista e excursionista que, por dedução, geralmente é estendido ao turismo em geral. Cunha (2003) enfatiza que a necessidade de criação de uma expressão própria para as pessoas que viajam por motivos de cultura, prazer ou repouso só se tornou efetiva quando esses deslocamentos se tornaram regulares e deram origem a atividades econômicas específicas. A tendência holística de conceituação do turismo também defendida por Ramos e Figueiredo (2008) se dedica a abordar a atividade como um fenômeno multidisciplinar e pluridisciplinar.

O turismo é uma atividade econômica que, como qualquer outra, desencadeia mudanças e transformações no local em que se desenvolve, principalmente 
quando se considera a mesma como um fenômeno social de contato intercultural. Esses impactos podem ser "positivos" ou "negativos" sendo difícil a separação daqueles ocasionados pelo turismo dos influenciados por outros fatores. (SILVA; FILHO, 2009). Nesse contexto, o turismo, na qualidade de prática social, é considerado como um dos principais fatores de modificação espacial. Dentro da abordagem dos impactos, estuda-se a capacidade intrínseca do turismo de transformar o espaço geográfico, seja por meio de alterações sociais, ambientais, culturais ou econômicas. Perez (2009) aponta alguns passos para o estudo e planificação dos impactos do turismo, destacando, desta forma, o estudo do contexto de desenvolvimento desses impactos: meio ambiente, cultura, sociedade e economia. Paiva (1995) sinaliza que a culminância dos efeitos da expansão da atividade turística se dá não apenas no nível econômico, mas também, numa dinâmica que engloba várias instâncias, sejam elas sociais, culturais, psicológicas e políticas. Esse fenômeno tem chamado à atenção do meio acadêmico e dos órgãos diretamente vinculados ao turismo, tendo em vista uma revisão do sentido do mesmo.

A intensificação da atividade turística, dentre seus principais desdobramentos, determina o contato ou o encontro entre a população local e turistas, promovendo a socialização entre eles, numa troca de vivências, valores, experiências e sensações. Seja comprando um bem ou serviço, ou simplesmente convivendo simultaneamente num espaço turístico, "os impactos socioculturais, numa atividade turística, são resultado das relações sociais mantidas durante a estadia dos visitantes, cuja intensidade e duração são afetadas por fatores espaciais e temporais restritos" (SANCHO, 2001, p. 215). Soldatelli (2005) afirma que a relação turista/morador local é caracterizada por alguns fatores que determinarão a qualidade do contato e as possíveis consequências advindas do mesmo. Dentre eles, destaca-se a transitoriedade da relação na qual o turista se vê encantado pela outra cultura, uma experiência exótica; enquanto os moradores percebem a situação de forma artificial.

Barreto (2004) aponta que os estudos acerca do impacto social da atividade turística se vinculam às ocorrências provocadas pelo contato intercultural entre visitantes e visitados, no conhecimento do outro, na relação de alteridade, além das mudanças percebidas por ambos os atores na relação turística. Pearce (2001), 
por meio de pesquisa sobre os efeitos do contato intercultural nos turistas, aponta diversas consequências observadas nessa relação nos mais variados contextos turísticos e destaca os impactos sociais e psicológicos da mudança no comportamento do turista. Mudança de percepção sobre as comunidades anfitriãs que passaram a ser avaliadas de forma mais positiva em relação à concepção anterior, além das alterações de saúde e bem-estar físico.

Segundo Aires e Fortes (2011), existem, de fato, poucos instrumentos e modelos de mensuração de impactos sociais, dentre os quais se pode citar, pelo valor considerável para a teoria do turismo, o ciclo de vida de uma destinação turística de Butler (1980), as fases do crescimento turístico de Fernández Fúster (1975) e o modelo evolutivo da mudança nas atitudes dos residentes para com os turistas, também conhecido como modelo ou índice de irritação de Doxey (1975). Segundo Barreto (2005), este último esquema é de suma importância, pois é uma ferramenta de grande aplicação na detecção dos impactos sociais, psicológicos e culturais. Desenvolvido com o intuito de captar e explicitar os impactos do desenvolvimento do turismo sobre as relações sociais, ele mostra por meio de uma cadeia cumulativa como se dá a mudança comportamental da população local de um dado destino em relação aos turistas.

Cruz (1996), ao estudar os impactos do turismo na Ilha de Cotijuba (PA), identifica a euforia dos moradores no que tange à implantação da atividade e à chegada de visitantes sinalizando a importância do controle e da organização dessa atividade. A percepção positiva em relação aos turistas facilita o desenvolvimento por meio de medidas turísticas de planejamento que beneficiam a população local. Esta demonstrou consciência à aplicação da atividade ao apoiá-la e impor limites e regras de intervenção dos planejadores e uso dos recursos. A percepção dos moradores em relação à interferência dos turistas na configuração das relações sociais internas e às influencias nos segmentos sociais revela impactos nas alternativas de recreação, infraestrutura básica ou segurança e nas formas de convivência familiar e comunitária.

Um dos principais desdobramentos do contato decorrente da atividade turística é o "efeito demonstração", que designa uma importante relação verificada nos contatos interculturais do turismo (IGNARRA, 1999). Essa atividade pode, ainda, dependendo das circunstâncias e das diretrizes sob as quais for 
instalada, originar oportunidades de afirmação da cultura local, garantindo a sua manutenção. Dentro dessa lógica, o turismo se apresenta como uma ferramenta de valorização da identidade local, aumentando a autoestima dos moradores, a valorização da culinária e das artes locais, o reconhecimento e a valorização da música e das manifestações culturais que caracterizam a comunidade. "No pensamento pós-moderno, a identidade é vista como algo móvel, sempre em construção, que vai sendo moldada no contato com o outro e na releitura permanente do universo circundante." (BARRETO, 2001, p. 19). Esse contato provoca um processo de contradições, tensões e questionamentos que, de forma sincrônica ou diacrônica, implica o fortalecimento da identidade e da cultura dos autóctones. Nesse sentido, a cultura do turista também se fortalece, pois, na alteridade, ele se redescobre (BARRETO, 2001).

\section{DIAMANTINA: CONTEXTO HISTÓRICO E DESENVOLVIMENTO DO TURISMO}

A origem e o nascimento da sociedade diamantinense remetem ao passado colonial brasileiro, haja vista que todo o povoamento e riqueza alcançados pela cidade se deram por meio, primeiramente, da extração de ouro e, num segundo momento, da descoberta e da exploração de diamantes no início do século XVIII. Esses recursos foram responsáveis por atrair um grande número de imigrantes principalmente paulistas, baianos e portugueses. A intensificação deste fluxo migratório fez com que a localidade se transformasse num arraial de grande importância comercial, configurando-se como um dos principais centros da economia mineiro-colonial (LIMA JUNIOR, 1978).

Segundo Martins (2000), a formação do Arraial do Tijuco ocorreu a partir da ligação territorial de quatro arraiais menores: o Arraial de Baixo, o de Cima, o do Rio Grande e o dos Forros, contribuindo para isto o fluxo migratório e a vinda de autoridades coloniais para a região. Em torno de todo o rebuliço social oriundo da descoberta e extração de diamantes, firmou-se uma legislação responsável por organizar e estruturar a exploração e a cobrança de impostos, bem como a permissão da extração diamantífera somente aos donos de escravos, que pagavam um tributo pela sua posse, e aos representantes da nobreza real 
no período compreendido entre 1729 e 1734. A partir de 1771, encerra-se a fase dos contratos. Com o objetivo de conter ao máximo o contrabando e a corrupção em torno da exploração das pedras preciosas, Diamantina passa a viver um período de regulação social e econômica por meio da instauração do Regimento Diamantino, também conhecido como Livro da Capa Verde, documento legislativo que estabelecia a privação e a restrição de todo o processo extrativista diamantífero ao Império Português.

A elevação do Arraial do Tijuco à condição de Vila se deu no ano de 1831 e à condição de cidade em 1835. Isso contribuiu para que a Real Extração deixasse de existir tornando livre a atividade garimpeira. Acrescente-se a isso o fato de o serviço controlador da Real Extração ter vivido momentos de crise a partir da terceira década do século XIX, sendo extinta oficialmente em 1832, parando de funcionar de fato em 1841. Livres para a exploração particular, os garimpeiros aproveitaram-se da situação. Minas valiosas foram descobertas e desbravadas em toda a parte no Pagão, no Córrego de São João, nos Caldeirões, no Quilombolas, no Curralinho, entre outros. Não foi possível conter a mineração nas terras do Distrito Diamantino, principalmente após a Independência, e os mineiros foram responsáveis pelo desenvolvimento de atividades como mineração, agricultura, construção de casas de vivenda e fábricas (MARTINS, 2000). "Este boom da mineração no antigo Distrito Diamantino durou até 1860, quando a entrada do diamante sul-africano no mercado internacional provocou grande baixa nos preços das pedras preciosas, lançando o município de Diamantina em nova crise." (MARTINS, 2000, p. 69).

Em face do declínio da atividade mineradora que, por mais de três séculos foi o sustentáculo da economia diamantinense, Diamantina se volta, cada vez mais, para a promoção de atividades ligadas ao setor terciário. Esse processo de transição econômica que, dentre outros fundamentos, prima pela tentativa de aproveitamento de outros recursos naturais como os hídricos e os paisagísticos, juntos com os recursos culturais e educacionais, marcados pelo valor e importância de sua história e cultura. Polo regional da atividade educacional principalmente universitária, a cidade conta com algumas faculdades e assiste ao nascimento da Universidade Federal dos Vales do Jequitinhonha e Mucuri, bem como sua ampliação anos depois. Nesse sentido, é preciso compreender a mudança de 
paradigma que orienta a economia local após a perda da sua principal atividade econômica para a construção de uma nova identidade sociocultural.

É no contexto de valorização e expansão da atividade turística no Brasil que a cidade de Diamantina descobre neste ramo econômico uma oportunidade para desenvolver a economia local. Cidade histórica, dotada de um grande patrimônio simbólico referenciado em seu conjunto arquitetônico secular, manifestações artísticas e culturais de importância histórica nacional, é capturada pelo turismo. Além disso, outro fator que impulsionou esse mercado e deu à cidade um selo de destino competitivo frente ao turismo nacional foi o título de cidade histórica Patrimônio Cultural da Humanidade concedida pela UNESCO no final do ano de 1999. Casario datado dos séculos XVIII e XIX, que não se encontrava descaracterizado radicalmente e contava com aproximadamente 500 imóveis inventariados. Em torno de um terço destes são do século XVIII e mais da metade encontra-se em bom estado de conservação. Fatores que posteriormente serviram de indutores da demanda turística representando o centro histórico um núcleo gerador de renda e recursos para os gerentes do trade turístico, dados os critérios de autenticidade, singularidade, excepcionalidade e originalidade.

Além disso, Diamantina é uma das cidades que compõe o tradicional roteiro das Cidades Históricas Mineiras, um dos produtos turísticos em desenvolvimento no estado, fazendo parte do Circuito Turístico dos Diamantes. Juntamente com ele, outro fator que justifica o destaque turístico diamantinense é a sua inclusão na área de influência da Estrada Real, denominado Caminho dos Diamantes. Esta rota liga o município a Ouro Preto sob a gerência do Instituto Estrada Real (IER) pertencente à Federação das Indústrias do Estado de Minas Gerais (FIEMG). Dentre os atrativos que a cidade de Diamantina apresenta ao turista se destacam o Carnaval e a Vesperata, eventos que movimentam um grande contingente de pessoas em períodos específicos do ano. Este último é atualmente o principal produto de comercialização turística de Diamantina. Criada na época da campanha de Diamantina à titulação de Patrimônio Mundial, é um evento de caráter musical realizado ao ar livre, na famosa Rua da Quitanda, vulgarmente conhecida por Baiúca. Essa atração denota o caráter musical da cultura diamantinense, presente em vários acontecimentos do cotidiano da cidade. 
Ao tratar do perfil da demanda turística de Diamantina e região, visando definir o segmento turístico local de acordo com os critérios geográficos, demográficos, socioeconômicos e comportamentais, Silveira, Maynart \& Medaglia (2013) apresentam que o turista de Diamantina é predominantemente regional, proveniente do próprio estado, adulto, equilibrado entre os sexos, com faixa etária entre 43 e 70 anos. De acordo com os critérios demográfico e socioeconômico, o público que frequenta a cidade apresenta certo equilíbrio e diversidade por obter certa similaridade nos níveis percentuais gerados. Esses turistas são descritos como exigentes, devido aos altos níveis de escolaridade e à faixa de renda acima da média nacional. Os turistas são adeptos do segmento de turismo cultural devido às características histórico-culturais e à oferta que procuram; mostram-se independentes, fazem um turismo de caráter familiar e são reincidentes no destino.

\section{METODOLOGIA}

O presente estudo é de natureza qualitativa e exploratória e pretende mapear os impactos psicossociais relacionados ao contato intercultural proporcionado pela atividade turística na comunidade de Diamantina, focando a discussão sobre as questões de identidade. Nesse contexto, definiram-se como colaboradores para compor a amostra da pesquisa representantes dos mais diversos setores ligados à atividade turística, nativos ou residentes antigos (mais de 10 anos) de Diamantina. Essa delimitação visou apreender a experiência desses profissionais/residentes no contato com os turistas. Primeiro, por meio de contato com as lideranças locais, foi feito um levantamento de participantes em potencial da pesquisa. Em seguida, realizou-se contato direto com pessoas que, pelo caráter de suas atividades, encontravam-se inseridas nos ramos de hospedagem, agenciamento, transporte e serviços de apoio ao turismo como entretenimento, eventos, guia de turismo, museologia, alimentação, ecoturismo, além do poder público por meio de membros da Secretaria de Cultura, Turismo (SECTur) e Patrimônio da Prefeitura Municipal de Diamantina, do Circuito dos Diamantes e do Serviço de Apoio à Micro e Pequena Empresa (Sebrae). Nesse momento, foi apresentada a proposta da pesquisa e foi feito o convite para 
a participação no grupo focal. Verificou-se a disponibilidade dos possíveis colaboradores, o que favoreceu o agendamento do encontro contemplando o maior número de convidados. O grupo focal foi realizado no final de 2011 na cidade de Diamantina.

Dessa forma, optou-se por utilizar a técnica do grupo focal que, segundo Cruz Neto et al. (2002), é:

\begin{abstract}
(...) uma técnica de pesquisa na qual o pesquisador reúne, num mesmo local e durante um certo período, uma determinada quantidade de pessoas que fazem parte do público-alvo de suas investigações, tendo como objetivo coletar, a partir do diálogo e do debate com e entre eles, informações acerca de um tema específico. (p. 5).
\end{abstract}

O grupo focal foi realizado com duração aproximada de duas horas. Foi composto por seis colaboradores representativos de diversos setores da atividade turística em Diamantina, a saber: um dono de hotel, um proprietário de atrativo turístico, um guia de turismo, uma agente de viagens, uma diretora de museu e um representante dos taxistas da cidade. Cinco deles são nativos de Diamantina e 1 vive e trabalha na cidade há 20 anos, o que atendeu ao critério de pertença ao universo cultural da cidade. Não compareceram 6 dos convidados que haviam confirmado presença.

As questões colocadas em pauta para provocar o debate foram: O que caracteriza o diamantinense? Como o turista enxerga o diamantinense? Como o diamantinense enxerga o turista? Quais impactos da atividade turística para o diamantinense? O debate foi mediado pelo professor-orientador com auxílio do aluno-pesquisador e foi registrado por meio fonográfico. Posteriormente, foi transcrito na íntegra para a análise. A análise se baseou no método de Análise de Conteúdo proposto por Bardin (2002).

\title{
APRESENTAÇÃO E ANÁLISE DOS RESULTADOS
}

Mediante análise do grupo focal em consonância com os objetivos propostos para este trabalho, foi possível identificar alguns indicadores sobre a identidade do diamantinense, que são recorrentes e aparecem como 
características unificadoras das pessoas que nasceram, habitam e se sentem parte dessa comunidade no contato com o turista. Essas características foram agrupadas em categorias que indicam a existência de três aspectos sob os quais se fundamentam a identidade do diamantinense: cultura garimpeira, cultura "refinada" e cultura da hospitalidade.

\section{CULTURA GARIMPEIRA}

A primeira categoria se apresenta fundamentada em características referentes à cultura garimpeira, muito referenciada nas falas dos entrevistados. "Então vira e mexe o perfil do diamantinense, para mim, tem que estar ligada ao garimpo." (E1, 2011).

Dado o caráter histórico do extrativismo mineral que moldou a estrutura do povo de Diamantina, a cultura garimpeira, dotada de tradição e de valores, constitui um referencial que faz parte da vida mesmo daquelas pessoas que não têm consciência e não reconhecem a importância que a atividade exerceu para a sustentação e consolidação dessa comunidade. Elementos que foram se moldando ao longo dos anos e repassados de geração a geração, praticados cotidianamente pelos moradores da cidade que sentiam orgulho de suas raízes, dos seus costumes, alimentando esse imaginário e contribuindo para que essa cultura não se perdesse no tempo.

Sou filho de Diamantina, tenho uma tradição garimpeira de muitos anos, mas ligado ao turismo eu estou apenas há quatro anos (...) isso tem despertado um interesse muito grande nas pessoas em conhecer o verdadeiro patrimônio de Diamantina, que é o garimpo. (...) Eu me sinto satisfeito em estar fazendo esse trabalho, porque afinal de contas, é a defesa de uma cultura. (E3, 2011).

Com relação ao que eles pensam da gente, eu acho muito curioso porque eles realmente têm a ideia de estar com um homem garimpeiro. Sabe, é tão curioso isso. Quantas pessoas já choraram ali, vocês acreditam? Quando vê a história, quando vê o diamante, aquilo ali é muito interessante. (...) aquilo é tão longe da realidade deles. (...) é isso que ele quer ver. $(E 1,2011)$.

O trabalho garimpeiro só se fazia possível graças à esperança, ao sonho e à vontade de um dia encontrar uma pedra preciosa que permitisse ao 
trabalhador mudar de vida. Essa possibilidade de enriquecimento rápido era o que alimentava a rotina diária de trabalho do homem garimpeiro, que se tornava refém desse ideário cultural, mas que nem sempre se tornava realidade. "Todo o garimpeiro que tem uma família que vem de garimpeiro, tem dentro daquela cultura, aquela esperança, aquela coisa que é o garimpo né, aquele sonho. Isso então às vezes passa de pai para filho". (E1, 2011). Respeito, dignidade e honestidade também são fatores que identificam o homem garimpeiro nas suas relações com o próximo, enfatizando princípios que se estabeleciam em acordos informais, não oficializados, que regiam a dinâmica social dessas pessoas. Existia compromisso, fidelidade entre as pessoas, o que se concretizava na responsabilidade em relação aos contratos firmados com o valor da palavra. Este aspecto do perfil do diamantinense está, portanto, relacionado aos procedimentos do garimpo.

São os procedimentos, é a maneira de agir. (...) a questão da honestidade que muita gente acha tão longe hoje. Quando a gente fala de determinados procedimentos que acontecem no garimpo, a palavra valia. Era o fio do bigode. Era um traço do diamantinense. Então você conseguia fazer um negócio ai na praça sem assinar. $O$ camarada falava e garantia. A questão do respeito. O comprador ou vendedor, quem fosse, ele era bem tratado, ele entrava na casa, saía, com todo o respeito. Era um traço do diamantinense. Uma boa leitura. Essas coisas tiveram sim ligadas a nossa atividade. Então é esse traço que nos define. (E1, 2011).

Nas colocações feitas pelos participantes do grupo focal nota-se que a cultura garimpeira é dotada de uma singularidade que a torna importante e reconhecida. Uma cultura particular, única e que se manteve viva durante séculos. Em torno dela se fundou a cidade, pois o garimpo proporcionou um grande fluxo de pessoas para o local. Cultura diferenciada que movimenta, em grande parte, a atividade turística da cidade.

Porque querer saber do diamante do ponto de vista geomorfológico, do ponto de vista físico, isso geralmente o turista já tem, ele traz, é um ou outro que talvez se interessaria por esse aspecto, ele quer saber sobre nós. O que é essa cidade? Que alma esse diamante, esse garimpo, moldou nessa cidade? Que é o que atrai as pessoas a vir a Diamantina. (E3, 2011). 
Outro aspecto da identidade diamantinense aparece definido como "cultura refinada", ou seja, um conjunto de características que fazem dessa cultura uma construção de caráter especial em detrimento das demais, por apresentar elementos que lhe dão um toque de sofisticação e requinte. Esse refinamento é produto de um processo histórico marcado por grandes contingentes de estrangeiros, uma vida social rica e diversificada, uma farta economia que, em torno da extração diamantífera, possibilitou um amplo giro de capital que nutria os privilégios e as regalias da nobreza que aqui vivia. Luxo e riqueza numa sociedade que tinha condições de adquirir produtos e serviços de qualidade oriundos da metrópole e manter uma vida de alto padrão. Isto se percebe numa cultura com ares europeus, com um patrimônio específico de influências portuguesas, grandes obras, muita leitura, um centro de poder do período colonial e que até hoje mantém essas qualidades.

O turismo lentamente quando começou, ele veio atrás dessa cultura, dessa marca registrada que Diamantina tem (...) se a gente não preservar a cultura que existe, que a gente ainda recebe um turista elitizado, que vem atrás da cultura, da tradição, da musicalidade, além da gente estar perdendo o que a cidade tem melhor, vai começar a receber um turismo de massa. (E2, 2011).

Esses elementos se fazem presentes na materialidade do centro histórico que conserva grande parte das características do período colonial. Esse conjunto arquitetônico e urbanístico revela também as estruturas sociais subjacentes à forma de ocupação do espaço urbano. Nesse sentido, o centro histórico é marco da cultura de uma classe dominante, europeizada, e não das camadas menos favorecidas da população. Nota-se uma aparente contradição entre essa cultura "refinada", orientada segundo padrões externos e a cultura local. No grupo focal a cultura "refinada" parece se sobrepor em relação à cultura sertaneja, regional, típica dessa porção mais interiorana do território mineiro, que não chega a ser mencionada.

A musicalidade de Diamantina, um fator determinante dessa cultura "refinada", encontra no Conservatório de Música Lobo de Mesquita e nos 
artistas locais (seresteiros, bandas, corais religiosos) a sua consolidação. Do projeto Diamantina Musical, criado para a campanha do Título de Patrimônio da Humanidade da UNESCO, encontram-se a Vesperata, o Circuito dos Corais, o Encontro Musical Lobo de Mesquita e o Encontro de Serestas, projeto esse realizado desde 2000. De acordo com o grupo focal, essa cultura musical tem um reconhecimento maior, ou seja, é ela o que também atrai os turistas. "Ele [o conservatório] também é detentor de um negócio forte que Diamantina tem que se chama a musicalidade aqui é forte." (E2, 2011).

Quando você fala da vinda de pessoas a procura de uma cultura, eu acho que se nós não resgatarmos a musicalidade que Diamantina tem, uma fama grande, e o turista vem, só vê carro de som, só vê tipo de música diferente daquela cultura que ele tá vindo buscar... (E2, 2011).

Outro elemento que reforça a ideia de uma cultura sofisticada são as referências à educação do povo de Diamantina. Um povo educado, bem instruído, escolarizado e que está em equilíbrio com a maioria dos visitantes, apontados como "sofisticados" e "selecionados". Ou seja, no encontro com esse turista, percebem-se reconhecidos como pessoas que possuem uma cultura que atrai esse público. Entretanto, esse aspecto é contraditório no discurso dos participantes do grupo focal, pois a educação precária é um dos elementos que mais se destacam como obstáculo para o desenvolvimento da atividade turística. Essa contradição pode indicar a percepção de duas categorias de diamantinenses, aqueles que possuem uma cultura "refinada" e aqueles que não possuem. Os primeiros contribuem para a atividade turística, os segundos atrapalham. O que se evidencia aqui é uma concepção de cultura associada à educação formal, a uma tradição erudita e intelectual, desconsiderando outros saberes, outras formas de expressão cultural.

Ao definir o público que vem à Diamantina como requintado e elitizado, indiretamente se exalta a própria cultura, uma vez que esse turista sabe procurar e valorizar o que é de qualidade. Esse olhar é reforçado pelos comentários e percepções dos turistas, que indicam certo "privilégio" de morar em Diamantina. Morar nessa cidade, por todas as raras e singulares características que ela apresenta, faz com que os diamantinenses se coloquem num patamar diferenciado em relação às demais comunidades. "A palavra que eu mais 
escuto deles (os turistas) é privilegiada." (E4, 2011). "Eles dizem que somos pessoas sortudas por morar num lugar belíssimo, que está assim com coisas mil para serem aproveitadas, e que a gente está com o tesouro (diamante) na mão". (E6, 2011).

\section{CULTURA DE HOSPITALIDADE}

O terceiro aspecto da identidade diamantinense evidenciado pelos participantes do grupo focal foi a cultura da hospitalidade. Ela se fundamenta no processo histórico de Diamantina que foi marcado pela chegada e pelo contato com o estrangeiro. Como apresentado anteriormente, desde a descoberta do ouro e do diamante no século XVIII, a cidade recebe um contingente de pessoas que vem para explorar os recursos da região. Essa exploração desenvolveu-se em três situações históricas específicas. No primeiro momento, vêm explorar os recursos minerais abundantes gerando um grande fluxo de bens e pessoas na cidade. Com o declínio da atividade garimpeira, passam a explorar outro recurso que é reflexo direto da atividade garimpeira: o patrimônio cultural em suas diversas expressões, favorecendo a estruturação da atividade turística. Em momento mais recente, outro fenômeno se apresenta como atrativo de pessoas para a cidade, a criação da UFVJM com ampliação dos cursos e construção do campus JK. Aumenta o fluxo de pessoas de diversas partes do país que se instalam na cidade seja para trabalhar ou estudar.

No que se refere à hospitalidade, evidenciam-se as virtudes do diamantinense no acolhimento ao outro. Amabilidade, gentileza, cortesia são qualidades que se destacam. Os visitantes lançam sobre o diamantinense um olhar positivo, dada a proximidade proporcionada pelas relações, e nesse contexto as qualidades do anfitrião se destacam. A solidariedade, o saber receber, o dom da ajuda, o acolher bem sem esperar nada em troca, fazem parte da essência do diamantinense.

Eu acho que eles veem os diamantinenses como pessoas educadas, gentis, estão sempre com um sorriso. Eles comentam muito que, de todos os lugares que eles foram servidos, podem até não saber abrir um vinho, podem até não saber servir corretamente, mas são corteses. (E3, 2011). 
Outra característica que reforça o caráter hospitaleiro da identidade diamantinense é a tranquilidade, o sossego com que as pessoas levam a vida na cidade. As pessoas têm liberdade de sair, se locomover sem correr grandes riscos num contexto urbano pacato, ao contrário da realidade da maioria dos visitantes, que reconhecem nessa particularidade um grande diferencial. $O$ modo de vida local possibilita uma estadia tranquila, sem ameaças, portanto acolhedora. Além disso, essa hospitalidade também se expressa por meio da culinária regional, muito apreciada pelo estrangeiro. Receber bem é servir bem à mesa, com fartura e especiarias locais.

A cidade de Diamantina é formada por um conjunto de atrativos naturais e históricos que por si só atrai muitas pessoas que vêm motivadas por diversas razões. Porém, nesse contexto migratório, há uma relativa contradição: ao mesmo tempo em que a cidade atraiu e acolheu diversos públicos ao longo do seu desenvolvimento histórico, ela não conseguiu integrar esses grupos, fazendo-os participar equitativamente da dinâmica urbana. Nesse sentido, Diamantina é definida como "uma cidade cingida pelas diferenças".

O restauro do mercado instaura para mim um novo tempo em Diamantina. O abandono. O mercado em Diamantina, nos anos $80 \mathrm{com}$ o Festival de Inverno, era o grande ponto de encontro de classes das mais diversas: do diamantário, do açougueiro, da prostituta, criança, cabia tudo, cabia todos ali no mercado. O restauro do mercado dá pano para manga pensá-lo do ponto de vista social, antropológico. (E3, 2011).

Segundo os participantes, a ocupação e a utilização dos espaços da cidade, de certa forma, definem os grupos que habitam esses espaços. Há diamantinenses que se utilizam do centro histórico que é dotado de uma realidade; existem também os moradores das áreas periféricas que possuem outro modo de vida e que não se incomodam com questões como o rápido crescimento do trânsito, porque não estão postas nesse contexto. Nesse sentido, há uma contradição entre uma cidade que recebe bem, acolhe, é amável, receptiva e gosta da interação com o diferente com uma cidade que não integra os imigrantes, não permite a inclusão social das pessoas que vivem nos espaços periféricos, isolados e distantes do centro histórico. 
Essa diversidade de relações é mais evidente quando se coloca nesse contexto o estrangeiro. O grande índice de pessoas que chegam para visitar, trabalhar ou morar em Diamantina ao longo do seu desenvolvimento gera na população a necessidade de interação de adaptação aos diferentes públicos. Mesmo com toda adversidade e os desafios naturais à convivência, o diamantinense mostra um estilo específico de sobrevivência:

É do diamantinense uma procura, (...) porque o diamantinense é muito aberto, ele gosta desse convívio com o outro. (...) Mas eu acho que ele é da procura. Recentemente, eu ouvi de um cineasta aqui no Festival de Inverno, ele levantou uma questão que eu achei muito interessante: que nós temos um sorriso. Independentemente das coisas estarem indo bem ou não, nós temos um sorriso. Que nós temos uma forma de viver, que até mesmo para falar das coisas, às vezes, muito amargas, a gente fala. São traços muito específicos mesmo dessa região de garimpo, que tem uma tradição histórica muito forte, que tem conflitos, que tem dificuldades às vezes com o diferente. $(E 3,2011)$.

Mediante a leitura dessas categorias é possível identificar a valorização das culturas garimpeira, hospitaleira e "refinada" na constituição da identidade diamantinense. No contato com o turista esses elementos parecem ser evidenciados e se apresentam como um patrimônio que precisa ser preservado. "Acho que as pessoas que vem, eles tem uma curiosidade com a gente, elas nos acham diferente, de um ponto positivo, nos acham diferente, mas de uma forma bacana, respeitosa, não vejo impacto com o turista, esse normal, normal, que eu digo, fora da data do carnaval." (E4, 2011).

Diamantina se manteve preservada, manteve a sua cultura que é o que fez a característica desse diamantinense. O turismo lentamente quando começou, ele veio atrás dessa cultura, dessa marca registrada que Diamantina tem e realmente esse conflito porque não está se pensando em preservar essa cultura que perece em acabar, vai acabar com essa qualidade de vida que nós estamos recebendo. É aquilo que eu acabei de falar: se a gente não preservar a cultura que existe, ué a gente ainda recebe um turista elitizado, que vem atrás da cultura, da tradição, da musicalidade. (E2, 2011). 


\section{CONSIDERAÇÕES FINAIS}

O presente trabalho surgiu da proposta de investigar a relação existente entre a comunidade de Diamantina e os turistas que frequentam a cidade, tendo em vista que este contato intercultural acarreta diversos impactos na dinâmica e o modo de vida local, enfocando nos impactos psicossociais que se sobressaem dessa relação, principalmente aqueles que afirmam a identidade cultural local. As transformações advindas deste encontro influem em diversos aspectos da vida do morador local e se manifestam de forma inconsciente no comportamento das pessoas. A mudança do ciclo econômico de Diamantina, do extrativismo mineral (garimpo) para o setor de serviços (turismo e universidade) tem repercussões profundas para o modo de vida local e, portanto, traz questões de ordem identitária. Em relação aos aspectos identitários decorrentes do contato intercultural com o turista, a análise da discussão produzida no grupo focal possibilitou a identificação de elementos culturais que afirmam a identidade tradicional local, resultando esses aspectos na configuração de três categorias: a cultura garimpeira, a cultura "refinada" e a cultura da hospitalidade. Todas elas refletem e afirmam a identidade do diamantinense.

A globalização gera um fluxo significativo de turistas que, em sua grande maioria, vêm em busca das particularidades e das excentricidades locais, numa prática espontânea que se contrapõe a uma das principais consequências da globalização que é a homogeneização cultural. Ou seja, percebe-se que a globalização gera um impacto que é o interesse pelo local, sendo mais correto pensar numa articulação entre o local e o global (HALL, 1999). Rocha e Monarstirsky (2008) destacam que o interesse pela preservação do patrimônio cultural em cidades que ainda contêm seus traços de origem pode corresponder a interesses econômicos de mercantilização turística ou a motivações ideológicas de conservação da memória e da identidade local. Assim, percebe-se que essa busca pelo local em face do global promove uma valorização da identidade local à medida que valores e características da comunidade são reconhecidos e enaltecidos pelos visitantes. No contexto deste trabalho, percebe-se o quanto certo tipo de turista valoriza a cultura local e reconhece o valor de todo o conjunto cultural sustentado por ela. 
A cultura garimpeira aparece como uma forma particular de lidar com a natureza e com as pessoas em geral, ressaltando não somente uma atividade econômica, mas também um modo de vida que orientou as relações sociais ao longo do tempo. Não diz respeito só ao garimpeiro, mas a todo um conjunto de atividades que se estruturaram em torno do garimpo, incluindo todos os segmentos da população. Esse aspecto é marcado pelo grande valor à tradição. Amparado pelos conceitos de tradição (HOBSBAUM, 2002) apresentados, fica clara a ideia de que há lugares em que essa tradição é mais forte e representativa, como, por exemplo, nas cidades históricas que, por meio da valorização e da preservação de seu patrimônio histórico original, consegue incultir nas pessoas os traços de um passado colonial que compõe sua infraestrutura original e que nunca se enfraquece. Diamantina se insere nesse contexto, pois em todas as partes há um elemento histórico que faz relembrar a história da cidade numa reafirmação da tradição.

A cultura "refinada", expressa em valores e costumes sofisticados, associadas a uma formação erudita, se consolida na imagem de uma cidade construída em torno da riqueza e do requinte. Marcos e registros de uma cultura nobre, elitizada que é descrita por Elaine Porto Guimarães (2006) como decorrente de uma concentração de poder e riqueza nas mãos de uma parcela privilegiada da população ligada aos negócios dos diamantes. Mesmo após o declínio da mineração, a autora argumenta que a comunidade local não perdeu seus traços originais, evidenciados numa índole culta, com aspectos de alegria em meio a uma sensibilidade para as expressões da arte e do espírito. Os aspectos dessa cultura refinada destacados no grupo focal como a pujança de um centro histórico, a educação do povo, e com maior ênfase, a musicalidade local, correspondem aos indicados nesses estudos de Guimarães (2006).

A terceira categoria desse eixo trata da cultura da hospitalidade que denota o caráter acolhedor e tranquilo do povo que habita Diamantina, sendo esta uma peculiaridade que atrai os turistas que frequentam a região. Desde a sua fundação, Diamantina conviveu com fluxos migratórios e com um expressivo contingente de visitantes de todas as partes do mundo, portanto, está na sua tradição a hospitalidade, o acolhimento do estrangeiro e do diverso.

Um aspecto que chama a atenção na análise do grupo focal é a ausência de referências ao caráter religioso, tão presente na constituição da cidade e 
da identidade do diamantinense. As referências religiosas encontram seus marcos nas edificações espalhadas ao longo da cidade e ajudam a compor o centro histórico, assim como nas manifestações e nos eventos religiosos que fazem parte do calendário turístico da cidade e nas expressões e nos costumes religiosos do dia a dia. Do ponto de vista da identidade, essa omissão pode ser justificada pelo fato de a religiosidade não ser nem afirmada nem confrontada no encontro com o turista. Portanto, nesse contexto, a religiosidade não se apresenta como uma questão identitária.

Outro aspecto de interesse é que existe uma contradição em relação à concepção do que é a comunidade de Diamantina. Nas falas dos participantes do grupo focal, se evidencia a existência de duas Diamantinas, dicotômicas entre si. De um lado, uma Diamantina idealizada, refinada, de tradições europeias e reconhecida pelo seu valor histórico e cultural. Uma cidade que se consolidou em torno de uma hegemonia econômica, de um passado colonial de muita riqueza e status que encontra seus remanescentes nas famílias mais tradicionais e antigas da cidade. Por outro lado, existe a Diamantina regional, sertaneja, com uma cultura representada pelas manifestações e pelos costumes característicos de camadas sociais mais populares e que até hoje não encontra espaço, nem é valorizada em suas tradições. São expressões das culturas negra, sertaneja, indígena e das regiões periféricas, de uma culinária vasta e miscigenada que não foi destacada por nenhum dos participantes.

Isto sugere que a concepção de cultura predominante no grupo não tem relação com o conceito antropológico de cultura, haja vista que os participantes consideraram a cultura como um sinônimo de erudição e como se fosse privilégio de um determinado grupo social. Nesse sentido, desconsideraram a cultura como processo de produção humana e, como tal, pode ser elaborada por qualquer agrupamento humano que vive em sociedade. Existem assim várias culturas. Não há uma restrição para a caracterização das culturas e todas têm o seu valor. Isto também pôde ser percebido pelos silenciamentos em torno da musicalidade típica dos grupos menos favorecidos da cidade, que não encontram representação frente aos demais. 
AIRES, Jussara Danielle Martins; FORTES, Lore. O Modelo Irridex de Doxey: breves considerações acerca de sua aplicação em Ponta Negra. Natal, RN: Revista Iberoamericana de Turismo- RITUR, Penedo, vol. 1, n. 1, p. 23-33, 2011. ISSN 2236-6040. Disponível em: http://www.seer.ufal.br/index.php/ritur. Acesso em: 15/09/2011.

BARDIN, Laurence. Análise de conteúdo. Trad. Luís Antero Reto e Augusto Pinheiro. Lisboa: Edições 70, 2002.

BARRETTO, Margarita. Planejamento responsável do turismo. Campinas: Papirus, 2005. $111 \mathrm{p}$.

BARRETO, Margarita Barreto. Turismo e Legado Cultural. Campinas: Papirus, 2001.

BARRETTO, Margarita. Relações entre visitantes e visitados: um retrospecto dos estudos sócio antropológicos. Revista Turismo em Análise. Vol 15, n. 2, nov. 2004, p.133-149.

BAUMAN, Zygmunt. Globalização: As conseqüências humanas. Rio de Janeiro: Jorge Zahar Editor, 1999.

BAUMAN, Zygmunt. Identidade: entrevista a Benedetto Vecchi/Zygmunt Bauman. Tradução de Carlos Alberto Medeiros. Rio de Janeiro: Jorge Zahar Ed., 2005.

BARRETTO, Margarita. Planejamento responsável do turismo. Campinas: Papirus, 2005. $111 \mathrm{p}$.

Beni, M. C. Análise estrutural do turismo. 6. ed. São Paulo: Senac, 2001.

CUNHA, Licínio. Introdução ao turismo. 2. ed. Lisboa: Verbo, 2003. 447 p.

CRUZ, S. H. R. Turismo na Ilha de Cotijuba sob a percepção de seus residentes. Revista Turismo em Analise: São Paulo, 1996. p. 79 a 92.

CRUZ NETO, Otávio; MOREIRA, Marcelo Rasga; SUCENA, Luiz Fernando Mazzei. Grupos Focais e Pesquisa Social Qualitativa: o debate orientado como técnica de investigação. In: XIII ENCONTRO DA ASSOCIAÇÃO BRASILEIRA DE ESTUDOS POPULACIONAIS, 13., 2002, Ouro Preto, MG: FIOCRUZ, p. 1-26, 4-8 de nov. 2002. Disponível em: <http://www.abep.nepo.unicamp.br/docs/ anais/pdf/2002/Com_JUV_PO27_Neto_texto.pdf > . Acesso em: 05/10/2011.

FONTOURA, S. R. H.; BECKER D. F. Turismo e Turista: uma viagem exploratória. Lajeado: Estudo e Debate. 1999 
GUIMARÃES, Elaine Porto. Estudo dos impactos causados pelo turismo de eventos culturais em localidades turísticas: o caso da Vesperata em Diamantina - MG. Belo horizonte: Centro Universitário UNA, 2006, 97 p. Dissertação (mestrado) - Programa de Mestrado em Turismo e Meio Ambiente, Centro Universitário UNA, Belo Horizonte, 2006. Disponível em: < http:// www.mestradoemtma.com.br/wp-content/uploads/2010/06/ESTUDO-DOS-IMPACTOSCAUSADOS-PELO-TURISMO-DE-EVENTOS-CULTURA.pdf>. Acesso em: 28/09/2011

HALL, Stuart. A identidade cultural na pós-modernidade. Tradução de Tomaz Tadeu da Silva, Guaracira Lopes Louro. 3. ed. Rio de Janeiro: DP\&A, 1999.

HALL, Stuart. A identidade cultural na pós-modernidade. Rio de Janeiro: DP\&A, 2000.

IGNARRA, Luiz Renato. Fundamentos do turismo. São Paulo: Pioneira, 1999.

HOBSBAWM, Eric; RANGER, Terence. A Invenção das Tradições. Rio de Janeiro: Paz e Terra.

JAPIASSÚ, Hilton; MARCONDES, Danilo. Dicionário básico de Filosofia. 3. ed. versão ampliada. Rio de Janeiro: Jorge Zahar Ed., 1996.

LIMA JUNIOR, Augusto de. A capitania das Minas Gerais. São Paulo: Editora Universidade de São Paulo, 1978.

MEDAGLIA, Juliana; MAYNART, Karla; SILVEIRA, Carlos. A Segmentação de Mercado e a Demanda Turística Real em Diamantina/ MG e Região. Revista Acadêmica Observatório de Inovação do Turismo, Rio de Janeiro, v. 7, n. 4, p. 54-75, 2013.

MARTINS, Marcos Lobato. Da bateia à enxada: Minas Gerais nos séculos XVIII e XIX. Diamantina: Ed. Fafidia, 2000.

PAIVA, Maria das Graças de Menezes V. Sociologia do turismo. Campinas: Papirus, 1995.

PÉREZ, Xerardo Pereiro. Turismo cultural: uma visão antropológica. Coleção Passos Edita. Tenerife, Espanha: ACA y PASOS, RTPC, n. 2, 2009. 307 p. Disponível em: <http://www. pasosonline.org/Publicados/pasosoedita/PSEdita2.pdf > Acesso em: 13/09/2011.

POLLAK, Michael. Memória e Identidade Social. Estudos Históricos. Rio de Janeiro, vol. 5, n. 10, 1992.

RAMOS, Karen Vieira; FIGUEIREDO, Antônio Marcus Lima. Contatos culturais no turismo: uma reflexão sobre os processos de aculturação. XXXI CONGRESSO BRASILEIRO DE CIÊNCIAS DA COMUNICAÇÃO, 31., 2 a 6 de nov. 2008, BA: UESC. Contatos culturais no turismo: uma reflexão sobre os processos de aculturação, Intercom: Sociedade Brasileira de Estudos 
ISSN: 1983-7151

Interdisciplinares da Comunicação. Natal, RN, 2008. Disponível em: < http://www.intercom. org.br/papers/nacionais/2008/resumos/R3-0999-2.pdf >. Acesso em: 08/10/2011.

RAYEL, Renata Salgado; GUIMARAES, Solange Terezinha de Lima. A valoração das paisagens protegidas de Diamantina (MG): premissa para o turismo cultural. Caderno de Geografia, v.22, n.38, 2013.

SANCHO, Amparo. Introdução ao turismo. 1. ed. São Paulo: Roca, 2001.

SANTOS, Reinaldo Soares dos. O Encanto da Lagoa: O imaginário histórico-cultural como elemento propulsor para o turismo cultural na Lagoa Encantada. Dissertação (Mestrado em Cultura e Turismo) - Programa de Pós-Graduação em Cultura e Turismo, UESC/UFBA, Ilhéus-Ba, 2004. Disponível em: <http://www.uesc.br/cursos/pos_graduacao/mestrado/ turismo/dissertacao/dissertacao_reinaldo_soares.pdf >. Acesso em: 10/09/2011.

SANTOS, Milton. A natureza do espaço: técnica, tempo, razão e emoção. São Paulo: Editora da Universidade de São Paulo (Edusp), 2002.

SILVA, Marcos Vieira, et.al. Certificação de Identidade Histórico-Cultural da Produção de Base Artesanal Mineira. Pesquisas e Práticas Psicossociais, São João Del-Rey, v. 1, n. 2, dez.2006. Disponível em: http://www.ufsj.edu.br/portalrepositorio/File/revistalapip/MarcoseValeria2. pdf. Acesso em: 26/08/2011.

SILVA, Karla Márcia da; FILHO, Nelson A. Quadros Vieira. Os resorts e seus impactos nas comunidades locais: estudo de caso das Águas do Treme Lake Resort no município de Inhaúma em Minas Gerais. Observatório de Inovação do Turismo. Revista Acadêmica, vol. IV, núm. 3, set. de 2009. Disponível em: http://bibliotecadigital.fgv.br/ojs/index.php/oit/ article/view/1594/1058. Acesso em: 16/08/2011

SOARES, Luís Augusto Severo. Turismo e globalização: algumas perspectivas. Revista Gerenciais, São Paulo, v. 6, n. 1, p. 63-70, 2007. Disponível em: <http://www.uninove.br/PDFs/Publicacoes/ revistagerenciais/rgerenciais_v6n1/rgerenciaisv6n1_3f04.pdf >. Acesso em: 17/10/2011

SOLDATELI, Márcio. Impactos ambientais negativos no contexto do turismo de natureza. In: TRIGO, Luiz Gonzaga Godoi et al. (eds.) Análises Regionais e globais do turismo brasileiro. São Paulo: Roca, 2005. 934 p.

SOUZA, Gisela; FILLIPO, Cynthia. Impactos socioculturais do turismo na comunidade de Tiradentes Minas Gerais. Revista Acadêmica do Senac Minas, v. 3, p. 1-21, 2006. Disponível em: http://www3.mg.senac.br/NR/rdonlyres/ ee6dfb3I7upa67zj3s3dpm3mtbearmvb33bwxvmoz4ucsx5ozr2fsywik6bfj36x5et2twfj7 g5h7p/cynthia.pdf. Acesso em: 18/10/2011. 
SWARBROOKE, John. Turismo sustentável: conceitos e impacto ambiental. Tradução de Margarete Dias Pulido. São Paulo: Aleph, 2000.

WEHLING, Arno \& WEHLING, Maria José. As estratégias da memória social. Brasilis: Revista de história sem fronteiras. Rio de Janeiro: Atlântida, ano 1, n. 1, 2003. 